\title{
Improving the Quality of Gaming Apps After Testing using Genetic Algorithm
}

\author{
Rijwan Khan, Pawan Kumar Sharma, Akhilesh Kumar Srivastava
}

\begin{abstract}
Software testing is a field to insure that delivery of any software or application in android is error free. Education program in Software Engineering aims at imparting skills among the students that focus upon meeting the expectations of the fluctuating needs of the industry. It has always been a worry about the skills and knowledge becoming outdated in a flash. The current article focuses the results and draws on experiences from improving the quality of a computer game after testing process using Genetic Algorithm. The quality of Gamming Apps can improve some areas of an individual like learning ability, problem solving, and sovereign learning and learn by doing. In order to better understand this research authors applied this change to 100 students which shows that they are good learner compare to others. The improved quality of the gamming also give the confidence to the parents that their child will learn in efficient manner.
\end{abstract}

Keywords: Gaming Apps, Testing, Unit Testing, Genetic Algorithm, Quality Checking

\section{INTRODUCTION}

An environment of mobility symbolized by Mobile devices along with the Apps running on such devices has grown like anything in the passing years [1]. Summarizes the need of the special attention by the Developers for the Mobile Apps [24]. The important problems have led to an increase of the present circumstances of the utilization of the mobile applications and to the development of the mobile applications in future [22]. The document is structured as: Section massive growth of the production of mobile devices is due to the quick growth of the mobile devices. There has been also an evolution of the sales in the last 20 years. In the section at present at international level there are presented models of utilization of mobile applications at international level. A number and different types of more used applications come from the on-line businesses. In the section there are presented the trends of utilization and the development in the applications of mobile telephony for the future trends of

Revised Manuscript Received on February 05, 2020.

* Correspondence Author

Rijwan Khan*, Department of Computer Science and Engineering, ABES Institute of Technology, Ghaziabad, Affiliated to AKTU Lucknow, India. Email: rijwankhan786@gmail.com

Pawan Kumar Sharma, Department of Applied Science, Krishna Engineering College, Ghaziabad, Affiliated to AKTU Lucknow, India. Email: vashistha23@gmail.com

Akhielsh Kumar Srivastava, Department of Computer Science and Engineering, ABES Engineering College, Ghaziabad, Affiliated to AKTU Lucknow, India. Email: joinakhliesh@yahoo.com

(C) The Authors. Published by Blue Eyes Intelligence Engineering and Sciences Publication (BEIESP). This is an open access article under the CC BY-NC-ND license (http://creativecommons.org/licenses/by-nc-nd/4.0/) utilization and the development of mobile applications on the grounds of the demands of the users and within the bounds of the restrictions imposed by the mobile devices project of development of mobile applications [23], the management of the quality of the process of development in the mobile environment are checked by tools of guarantee of the quality. Also the factors that influence the quality of the management in projects of development of mobile applications are presented. The document ends with the section Conclusion.

\section{THE RESION FOR THE ACCELERATED GROWTH OF MOBILE DEVICE USAGE}

The first cell-phone has been thrown in 1973 in model Motorola, Motorola DynaTAC. In the 90s they have become disposable to the public and their diffusion has begun. In the last years the production of mobile devices has had an explosive growth. In [2] there is presented the evolution of the sales of cell-phones in the period 1992-2012. The competition and the diffuse use have increased do not be in other electric devices or technical productions in the cell-phones production 20 years.

\section{QUALITY ASSURANCE TOOLS IN MOBILE APPLICATION DEVELOPMENT PROJECTS}

The process of development of the software is not a repetitive enterprise [3]. Each realized software presents different characteristics ensuing from the way in which it has been planned, the way in which the code has been written and commented, the way in which the tests have been led or the used development methodology. The models of quality and the pertinent standards can be reached through the assurance of the quality that cannot be organized and implementation to the same way of the lines of production, repeating the same process. The principal objective of the assurance of the quality in the development of the software is turned to the development and not to the production [3, 15, 17]. In succession there are brought back some problems that are faced by the guarantee of the quality in the mobile application: - quality of the management - quality of the development $\bullet$ quality of the tests.

\section{MANAGEMENT QUALITY}

All the factors involved need to be thoroughly analyzed for the proper quality. The management process of mobile application development is been influenced by:

- owner

- end-user

- project team

- legal framework

- competition 


\section{Improving the Quality of Gaming Apps After Testing using Genetic Algorithm}

- previous experience

- market

- budget

- deadlines

In Figure 1 it is shown how various factors influence the quality of management in a mobile application development project.

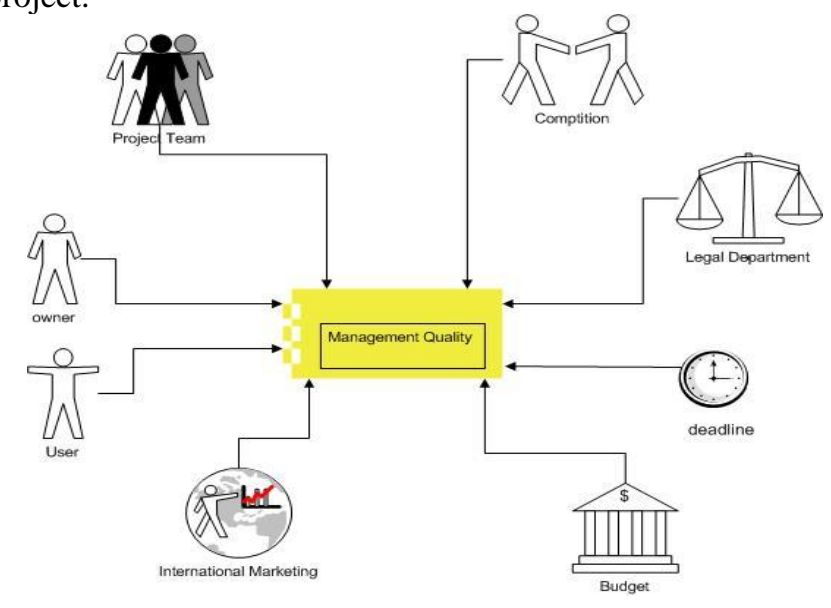

Fig. 1. Management process quality

\section{A. Owner}

The Project is initiated, financed, benefited by the owner. There should not be any confusion between the owner and the project manager as they are different entities even when developing an internal project [4]. The quality of the project management can be adversely affected by the owner by giving confusions or incomplete specifications. This can lead to plot unsuitable work scenarios and inaccurate project planning. In the detailed bills of the initial project the frequent modifications are brought by the owner, causing delays in the tension development and dissatisfied in the team of the project that additional costs create also. This can have a negative impact on the quality of the project ignoring or delaying the payments or without supplying adequate resources. The development can be blocked temporarily in case of delays and can involve also additional costs.

\section{B. End-user}

It is the persons who use the applications on their mobile devices. They supply the pertinent feedback and influence positively the quality of the management of a development of mobile applications. If the pertinent feedback relative to the application has positive result, it is possible to correct some wishes during the phase of planning or development. Based on the reviews, the manager can modify the detailed invoices and guide all the development efforts towards the pertinent functionality. There have become significant strength points in the field of the present programming. As asserted in [5], they are developing the own applications, generally the staff. The applications can supply important information about for what the end users ask really to the mobile software.

\section{Project team}

It is composed by the persons who are actively involved in the project: project manager, planners, tester, graphs and analysts of the usability. The members of the team of project have a positive impact on the quality of the project and of the process of management when they formulate proposals of improvement, methods of optimization and innovative ideas. I am the perfect example of synergy in which the collaborative work will guarantee turned out to be significantly faster than the individual work. The efforts of the member of the team should be aligned to the objective of the project in the way of being able to obtain the best possible quality [6].

\section{Legal framework}

It is composed out of all the laws to which the project is subject to. The quality of the project is influenced negatively when it is led in a coercive environment. They change constantly the way in which the developers supply and create applications. The legislation influences the way, in which the software is used, developed supplemented, reutilized and distributed [7]. The management process can be damaged at an excessive bureaucracy since the efforts of the responsible person of the project concentrate on the legal formalities and less on the general quality of the project.

\section{E. Competition}

It consists in mobile applications that aim at the same objective, same public and applications with similar functionality that are necessary to be developed. On the management process it has a positive impact in returning public the data and the reliable information about the mobile applications previously you throw. In this scenery, the errors committed by the competitors can be avoided at the project manager and obtain to their results.

\section{F. Previous experience}

Projects that are conducted or on which implementation have been done by the manager come under this. Supplying answers when manager was meeting common or similar elements from the project with the help of the experience in this field, we can have a positive impact on the quality of the process of management [16]. The mobile application that must be developed at the project manager must be developed when the manager applies all his knowledge and past experiences.

\section{G. Market}

It is the development of mobile applications of the harvesting that defines the elements of the environment. The process of quality of the management is influenced by the increase of the technology that is changing, the speed with which the mobile terminals are thrown and the diversity of the technical characteristics. To adapt to the short cycle of the software, the project manager must know the last technologies on the market. Such applications must be developed at low price and on times extremely limit, often sacrificing the quality.

\section{H. Budget}

It consists in all the financial resources and in the material picked up to develop and to carry the project out. During the development of a mobile application, the project manager must take the budget tie into account. The quality of the management must not be influenced at the budget of the project. 
The just budget will increase the total quality of the process of management supplying the access for several tools to which it is possible to enter only paying a commission. Such tools are: - software of management of the projects: Microsoft Project, Spring Project Management; • software of management of the risks: @Risk, Active Risk Manager; • software of assignation of the activities and of progress: Pivotal Tracker.

\section{Deadlines}

It is the important constraint for the project managers and is often associated with milestones. For a project it is the principal points of reference that mark the end of a phase of planning, development or test. Passages and mile stones are payments strictly allies made by the owner of the project. The delays in the payments and the penalties are due to delays in the delivery of the question. The principal stress factor for the project manager and the members of the team he is Deadline. Often it can inhibit the creativity and the innovation. The deadlines help the team to concentrate on important tasks and mobilize the persons when the project is in a difficult situation.

Table-I: Influencing factors of project management

\begin{tabular}{|c|c|c|}
\hline FACTORS & POSITVE & NEGATIVE \\
\hline Owner & $*$ & $\begin{array}{c}\text {-confusing or } \\
\text { incomplete } \\
\text { specifications } \\
\text {-change specifications } \\
\text {-late payment }\end{array}$ \\
\hline End User & -feedback & * \\
\hline Project Team & $\begin{array}{l}\text {-improvement } \\
\text { proposals }\end{array}$ & $*$ \\
\hline Legal Framework & $*$ & $\begin{array}{c}\text {-excessive } \\
\text { bureaucracy }\end{array}$ \\
\hline Competition & $\begin{array}{l}\text {-provides data and } \\
\text { information }\end{array}$ & $*$ \\
\hline Previous Experience & $\begin{array}{c}\text {-source of inspiration } \\
\text {-knowledge and } \\
\text { experience transfer }\end{array}$ & * \\
\hline Market & & $\begin{array}{c}\text {-rapid technological } \\
\text { change } \\
\text {-applications with } \\
\text { short life cycle }\end{array}$ \\
\hline Budget & & $\begin{array}{l}\text {-Management } \\
\text { software tools }\end{array}$ \\
\hline Deadlines & -increase productivity & -inhibit creativity \\
\hline
\end{tabular}

The field of the development of mobile applications is an area that has earned recently a reputation $[18,19]$ and then it you is a relative lack of standard of quality in the sector.

Each unity of development is an entity composed by two parts: the planner and the environment of development. The development environment can be held locally on the computer of the planner or on-line on a server of development shared with other developers.

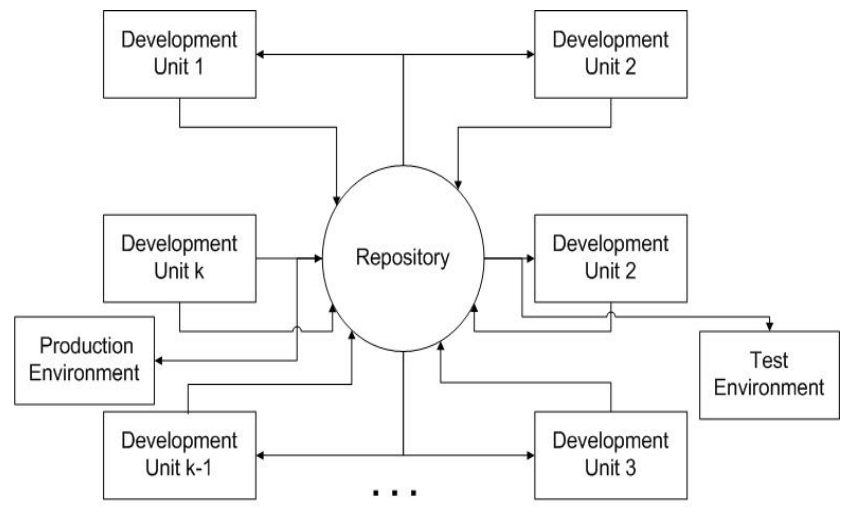

Fig. 2.The quality of mobile application development process

This application will run by production environment. The test environment must be the exact copy of the environment of production. We check Ud as the whole of the unities of development [16]:

$\mathrm{Ud}=\{\mathrm{ud} 1, \mathrm{ud} 2, \mathrm{ud} 3, \ldots . \mathrm{udk} \ldots \mathrm{udmk}\}$

Where:

udk - is the development unit $\mathrm{k}$ in a mobile application development project

$\mathrm{nu}$ - is the total number of development units.

Consider $\mathrm{Ak}$ as the set of updates performed by a programmer:

$\mathrm{Ak}=\{\mathrm{ak} 1, \mathrm{ak} 2, \mathrm{ak} 3 \ldots$ aki...aknk $\}$

aki - is the update i performed by development unit $\mathrm{k}$.

$\mathrm{nk}$ - is the number of updates performed by development unit $\mathrm{k}$.

Consider Ik as the set of source code uploads performed by a programmer

$\mathrm{Ik}=\{\mathrm{ik} 1, \mathrm{ik} 2, \mathrm{ik} 3 \ldots \mathrm{ikj} \ldots \mathrm{ikmk}\}$

Where:

$\mathrm{ikj}$ - is the upload j performed by development unit $\mathrm{k}$.

$\mathrm{mk}$ - is the total number of uploads performed by development unit $\mathrm{k}$.

Under ideal conditions updates and uploads performed by development unit $\mathrm{k}$ must comply with the following rule $\sum_{j=1}^{n k} a_{k j}=\sum_{j=1}^{m k} i_{k j}$

The programmer before starting work on a task downloads the most recent version of the source code to represent the development unit k. Besides, for each completed activity a single loading will be carried out. In conditions of environment of real development, the loading and the updating carried out by the unity of development $\mathrm{k}$ are conformable to the next rule:

$$
\sum_{j=1}^{n k} a_{k j}<\sum_{j=1}^{m k} i_{k j}
$$

The programmer before starting work on a task downloads the most recent version of the source code to represent the development unit k. Multiple uploads will be done after every completion of task. The quality of the mobile applications is strongly correlated to the degree of innovation that it incorporates. The innovative projects are those that define the standards and the most elevated quality standards are translated in more reliable and economic software. 


\section{Improving the Quality of Gaming Apps After Testing using Genetic Algorithm}

\section{CHALLENGES AND OPPORTUNITIES OF COMPUTER GAMES}

Exercises in games or the inspired games have been used in have been used in programming courses for a while [8, 9, 10,11]. Using games in SEE has a lot reasons itself. First, it has the ability to motivate learners. According to Sindre et al, these exercises motivate students at ease and are more fun. Ferrari, Taylor and Van Lehn (1999) [12], stated that lessons learned from games make it memorable. Because the students are considered to be the end users for games, they can differentiate user-interface approaches among various games that they have experienced in past several years. This elevated experience degree increases the quality of these programs in terms of usability [13]. Besides, the games are justified by the students to be worked continuously and to improve their abilities. The students can keep on using and improve their products after the deadline, while the greatest part of other programs of exercises is delivered and then been forgotten by them [13]. The visualization is an essential tool in SEE, since it is used in the design, creation and interpretation of the knowledge. The games for computer allow to the students to meet techniques of visualization and of worry in formats with growing difficulty levels, and the games challenge the students to develop a level more advanced of comprehension. All kind of topics are covered in SE curriculum that one wants [14].

\section{GENETIC ALGORITHM}

The idea of the genetic algorithm has been developed in 1975 in Holland at the book "Adaptation to the natural and artificial systems". Holland has described how to apply the algorithms to the natural evolution to the optimization problems and has created the first genetic algorithms [25]. To solve the problems of research and optimization, Holland has developed later on his theory and has found the genetic algorithms (GA) as a powerful tool. On the beginning of the genetics and of the evolution genetic algorithms are based. "Survival of the fittest" is the theme on which the heuristic method is based. The problem of the optimization is solved by the genetic algorithm that is an evaluative algorithm [20, 21]. With GA we find approximate solutions of the problems of optimization. The possible solutions of the population are managed by him. The representation of each solution happens through a chromosome, which is an abstract representation. The genetic algorithm turns on one to make evolving the population in the iteration process. The next passages are involved in each iteration:

(i) Initialize population;

(ii) Evaluate population;

(iii) While Termination Criteria Not Satisfied

(iv) Then select parents for reproduction;

(v) Perform recombination and mutation;

(vi) Evaluate population; [20, 21]

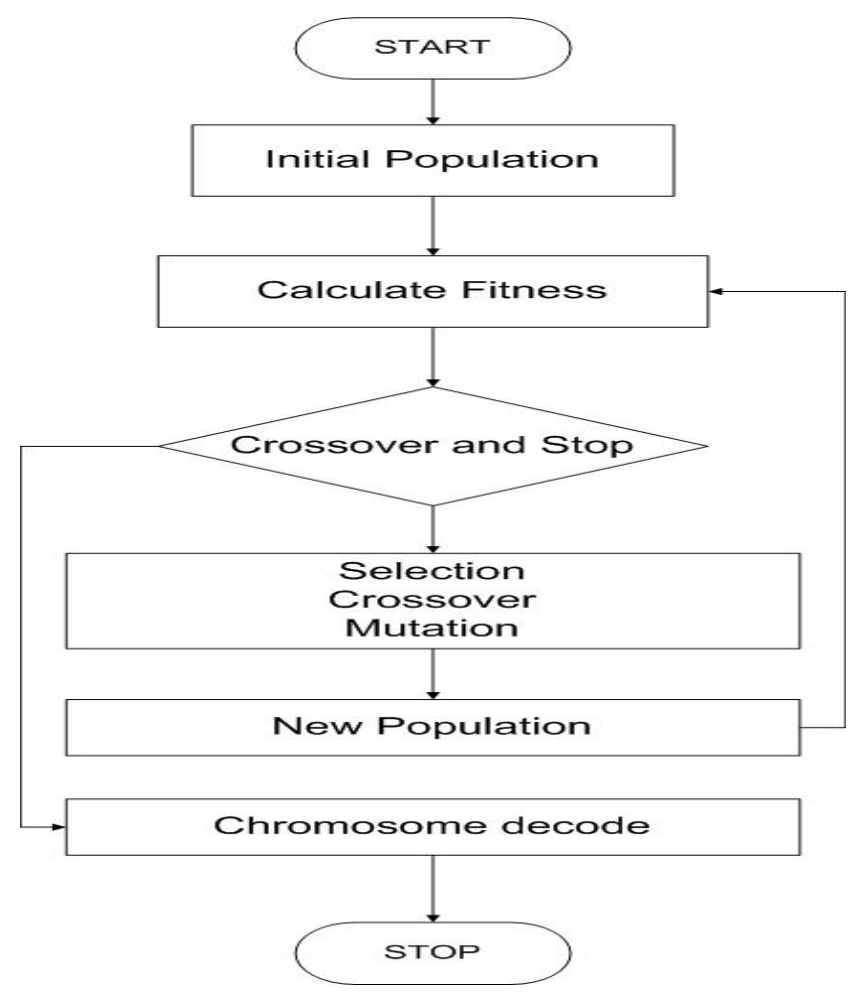

Fig. 3. Genetic Algorithm

\section{PROPOSED METHOD}

In this a scenario is developed for the player and then tested with GA for improvement of quality.

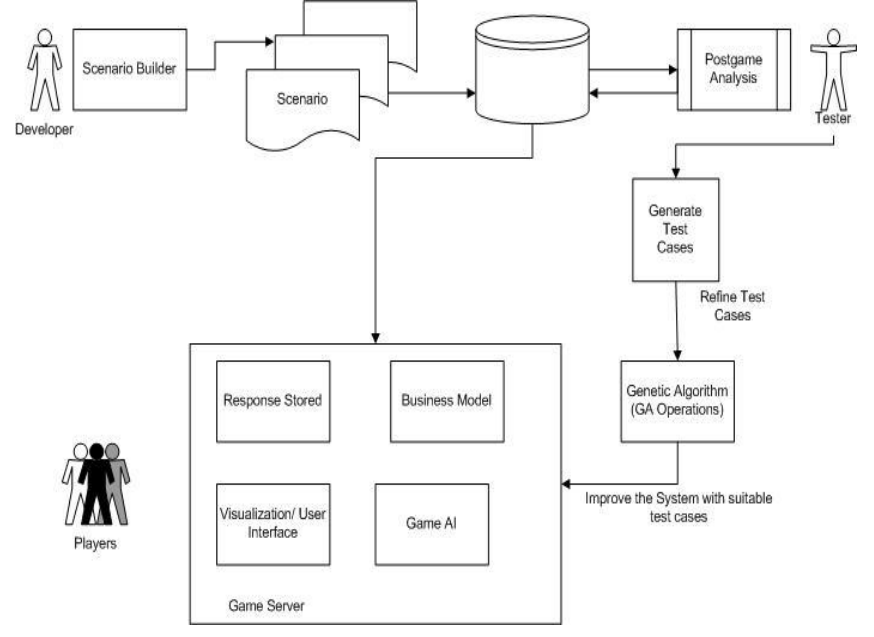

Fig. 4. Players Scenario with response storage and QA with GA

To create or update the game scenarios we use Scenario Builder which is an offline tool. In server-side database scenarios are stored.

- Postgame Analysis is another utility offline that allows us to supply data to the facilitator on the performances of the team. It will supply also the impact with the game and will produce longitudinal analyses with the help of the data.

- There are four sub main systems of the Game server:

- The response stored allows each player to be in touch with each other and further their responses are also stored. 
- The Visualization/User Interface manages what the players can see on the screen and what they can do.

- The company model, which it carries out either the general commercial rules or the specific commercial rules referred to each scenery.

- The Game AI, which executes Payers automatically.

The main work of tester is to generate the test cases and refine these cases with the help of genetic algorithm to improve system quality.

\section{RESULT ANALYSIS}

When GA with longitudinal analysis and visualization is applied on data set 1 , the different users were visualized as shown in figure 5 and for data set 2 it is clear shown in figure 6.

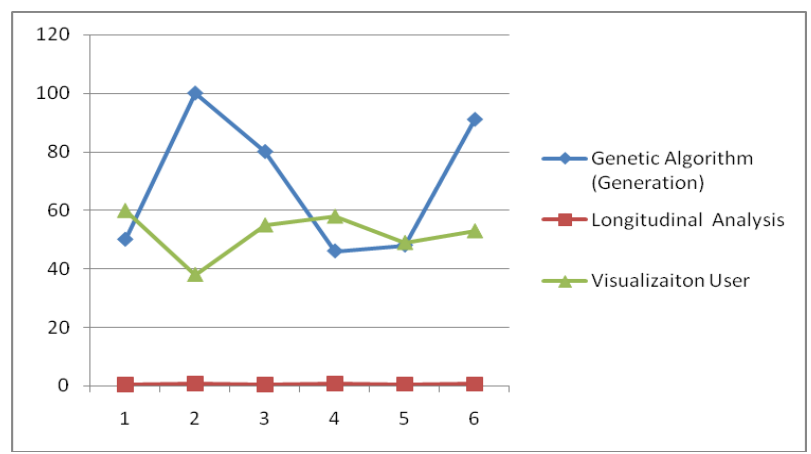

Fig. 5. GA with Longitudinal Analysis

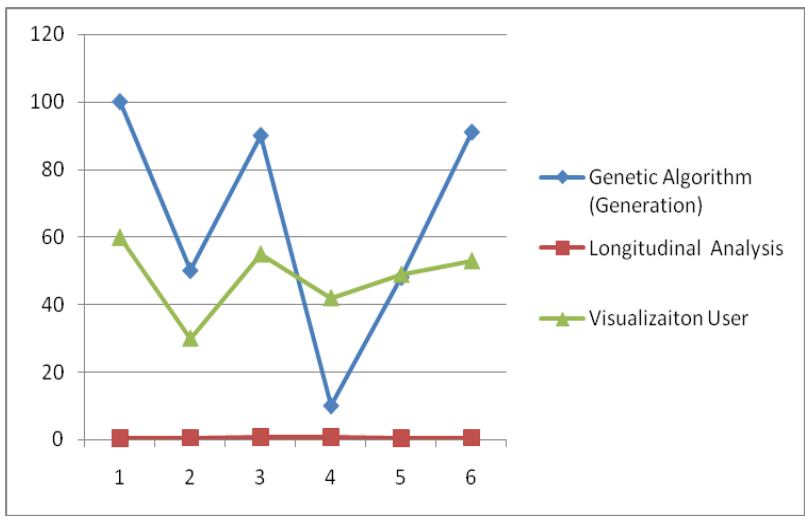

Fig. 6. GA with Visualizaiton users

\section{CONCLUSION}

In this document, we have examined the preceding approaches to the application of the learning based on the games to the engineering of the software and have found a significant want of empiric research to support of this approach. The engineering of the software has been described like a "wicked problem" characterized by incomplete, contradictory and changeable requirements and solutions that often are difficult to be recognized like them because of complex interdependences. Other questions that complicate the teaching of the engineering of the software are that the development of the software is not linear, it implies different passages intermediate and choices between more practicable alternatives, can present dramatic effects with invisible causes and it involves more stakeholder. At last, we have described the design of a new application of learning based on games turned to improve the quality of the student and the game apps. The authors think that the evaluation is the key of the whole process of development and have adopted and applied operations of genetic basic algorithms to generate new cases of test. These cases of test are applied to the system so that it could improve the quality it.

\section{REFERENCES}

1. L. Hall, A. Gordon, L. Newall, R. James, "A development environment for Intelligent Applications on Mobile Devices", Expert Systems with Applications, vol. 27, no. 3. 2004, pp. 481-492.

2. http://en.wikipedia.org/wiki/List_of_bestselling_mobile_phones.

3. V. R. Basili, G. Caldiera - Improve software quality by reusing knowledge and experience, 2012, Sloan Management Review, vol. 37.

4. R. Muller, J. R. Turner - The impact of principal-agent relationship and contract type on communication between project owner and manager, 2005, International Journal of Project Management, vol. 23, pp. 398-403.

5. A. J. Ko, R. Abraham, L. Beckwith, A. Blackwell, M. Burnett, M. Erwig, C. Scaffidi, J. Lawrance, H. Lieberman, B. Myers, M. B. Rosson, G. Rothermel, M. Shaw, S. Wiedenbeck - The state of the art in end-user software engineering, ACM Computing Surveys, April 2011, vol. 43, issue 3.

6. A. Cockburn - Agile software development, the people factor, The Agile Software Development Series Cockburn Highsmith Series Editors, 2001, pages 88- 89 .

7. D. M. German, J. H. Webber, M. Di Penta - Lawful Software Engineering, Proceedings of the FSE/SDP workshop on Future of software engineering research, Santa Fe, New Mexico, USA, November 07 - 11, 2010 , pp. 129-132 , ISBN: 978- 1-4503-0427-6.

8. Adams, J. C. (1998). Chance-it: An object-oriented capstone project for CS-1. In Proceeding 29 ${ }^{\text {th }}$ ACM Special Interest Group on Computer Science Education (SIGCSE) technical symposium on Computer science education, Atlanta, Georgia, United States (pp. 10-14) NewYork: ACM Press.

9. Baker, A., Navarro, E. O. \& Hoek, A. V. D. (2005). An experimental card game for teaching

software engineering processes. The Journal of Systems and Software, 75, 3-16.

10. Becker, K. (2001). Teaching with games: the Minesweeper and Asteroids experience. Journal of Computing Sciences in Colleges, 17, 2, 22-32.

11. Bidarra, R., Dalen, R. V. \& Zwieten, J. V. (2003). A computer graphics pioneer project on computer games. In Proceeding Workshop Computaçao Grafica Multimedia Ensino-CGME, Workshop on Computer Graphics, Multimedia and Education, October 8, Porto, Portugal (pp. 61-65).

12. Ferrari, M., Taylor, R. \& VanLehn, K. (1999). Adapting work simulations for schools. The Journal of Educational Computing Research, 21, 1, 25-53.

13. Sindre, G., Line, S. \& Valvag, O. V. (2003). Positive experiences with an open project assignment in an introductory programming course. In Proceeding 25th International Conference on Software Engineering (ICSE '03), Portland, Oregon (pp. 608-613). Washington, DC: IEEE, Computer Society.

14. Jones, R. M. (2000). Design and implementation of computer games: a capstone course for undergraduate computer science education. In Proc. 31st SIGCSE Symposium in Computer Science Education, Austin, TX, March 2000.

15. Thomas M. Connolly, An application of games-based learning within software engineering, British Journal of Educational Technology Vol 38 No 32007 pp 416-428.

16. Zamfiroiu, Alin, and Mihai Liviu Despa. "Reasons, Circumstances and Innovative Trends in Mobile Environments." Informatica Economica 17.2 (2013).

17. Cagiltay, Nergiz Ercil. "Teaching software engineering by means of computer-game development: Challenges and opportunities." British Journal of Educational Technology 38.3 (2007): 405-415.

18. Ampatzoglou, Apostolos, and Ioannis Stamelos. "Software engineering research for computer games: A systematic review." Information and Software Technology 52.9 (2010): 888-901. 
19. Palos-Sanchez, Pedro, et al. "Users acceptance of location-based marketing apps in tourism sector: An exploratory analysis." Journal of Spatial and Organizational Dynamics 6.3 (2018): 258-270.

20. Khan, Rijwan, and Mohd Amjad. "Automatic test case generation for unit software testing using genetic algorithm and mutation analysis." 2015 IEEE UP Section Conference on Electrical Computer and Electronics (UPCON). IEEE, 2015.

21. Khan, Rijwan, and Mohd Amjad. "Mutation-based genetic algorithm for efficiency optimisation of unit testing." International Journal of Advanced Intelligence Paradigms 12.3-4 (2019): 254-265.

22. Connolly, Thomas M., Mark Stansfield, and Thomas Hainey. "An application of games-based learning within software engineering." British Journal of Educational Technology 38.3 (2007): 416-428.

23. Zimmeck, Sebastian, et al. "Automated analysis of privacy requirements for mobile apps." 2016 AAAI Fall Symposium Series. 2016.

24. Ali-Gombe, Aisha, et al. "Aspectdroid: Android app analysis system." Proceedings of the Sixth ACM Conference on Data and Application Security and Privacy. ACM, 2016.

25. Gupta, Indresh Kumar, Vikash Yadav, and Sushil Kumar. "Medical data clustering based on particle swarm optimisation and genetic algorithm." International Journal of Advanced Intelligence Paradigms 14.3-4 (2019): 345-358.

\section{AUTHORS PROFILE}

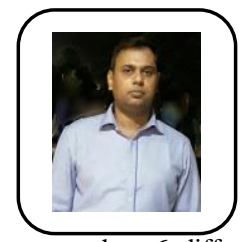

Dr. Rijwan Khan, is B.Tech (CSE), M.Tech (CSE) and Ph.D in Computer Engineering. He has total 13 years of teaching experience. Now working as a Head of Department in ABES Institute of Technology. His are of research is software testing, soft computing, nature inspired algorithms. He published more than 25 research papers in different journals. He is reviewer of more than 6 different Scopus and SCI indexed journals like journals of Inderscience, Springer, and Elsevier etc. He is authors of 3 books on $C$ Programming, Data Structure using C, and Operating System and one book chapter in springer book.

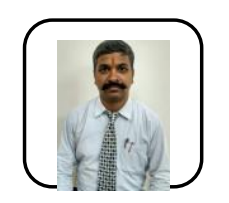

Dr. Pawan Kumar Sharma, has completed his Ph.D. in Reliability Theory (Operations Research). He had done his research work on Operations Research and Graph Theory where he published research papers. He also published two research papers on Fuzzy graph \& Image Processing. Currently he is actively involved in Birla Institute of Technology \& Science, Pilani (Rajsthan) as a Guest Faculty for working professionals \& INMANTEC Institutions Ghaziabad. He has more than 14 years of teaching learning \& research experience of graduate \& post graduate classes. Proven Expertise in designing/restructuring course outline, material and assessment criteria and implementing innovative instruction methodologies to match international standards.

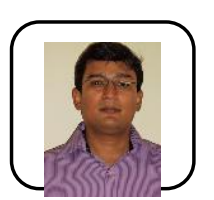

Mr. Akhilesh Kumar Srivastava, is a Computer Science Graduate from K.N.I.T. Sultanpur and Post Graduate from Dr APJ Abdul Kalam Technical University Lucknow. He is registered for PhD at UPES Dehradun. Author is GATE and UGC Net Qualified. He has authored 3 Books and several research Papers in International/ National Journals, presented papers in International Conferences. Author runs his own You Tube Educational Channel with substantial viewership across the globe. 